are central for inspired and critical discussions about the pressing problems of our world today, without the anachronism and discursive abstraction of much political commentary. To paraphrase the concluding paragraph of The History Manifesto: we urgently need the wide-angle, long-range views only historical museums can provide.

\title{
Time, Impact, and the Need for Digital History and Philosophy of Science
}

\author{
by Jane Maienschein
}

Thenticer hank you, Cambridge University Press, for giving us this book with a Creative Commons license. Thank you, Jo Guldi and David Armitage, for thinking big and provoking others to do so. Many responses to The History Manifesto embrace at least some of the messages offered in this extended essay.

The Manifesto is just that: a call to arms, for several different things. First, and for most readers foremost, the authors call for long-term thinking. They claim that historians have moved to short-termism, with loss of relevance outside the small-scale studies themselves. A number of historians have responded to this claim with the equivalent of "Historians have so too been doing long-term thinking. Such-and-such examples prove it. So nyah-nyah, you are wrong." This largely misses the point-namely, that whether or not there has in fact been a change to shorter-term thinking, most dissertations in all fields do focus narrowly because students are encouraged to do so. Focus, focus, focus. And that's not bad.

The second and related point seems more worrisome for the manifesto authors. They see historians' short-termism as bad for the profession in part because the public and policy makers need long-term thinking. They feel that public actors don't draw on historical scholarshipand that they should. This becomes an imperative: "Historians of the world, unite! There is a world to win-before it's too late."22 It seems that all historians should embrace the longue durée, take on the public roles that they will magically be invited to assume-and they can then inform political figures who need their long-term thinking.

In fact, there is something more going on in the book. It contains an unstated assumption that historical scholarship should be more applied, in the sense of being made more useful and therefore more used. Instead of urging everyone to "go long," we might call for more clearly articulated "So what?" discussion about why a study matters. A meticulously documented shortterm study might actually be quite valuable, with reflection about how it connects to the longer term and about implications of the results for public matters. Perhaps the authors would accept that history (and perhaps all humanities fields) should join the NSF, NIH, and other federal

Jane Maienschein is University Professor, Regents' Professor, President's Professor, and Parents Association Professor at Arizona State University, where she is also Director of the Center for Biology and Society, and a Fellow at the Marine Biological Laboratory. Her main area of research is the history and philosophy of developmental biology. Her most recent book is Embryos under the Microscope: The Diverging Meanings of Life (Harvard University Press, 2014). Center for Biology and Society, School of Life Sciences, Arizona State University, Tempe, Arizona, and Marine Biological Laboratory, Woods Hole, Massachusetts; maienschein@asu.edu.

${ }^{22}$ Jo Guldi and David Armitage, The History Manifesto, http://historymanifesto.cambridge.org/download/ (Feb. 2015$)$, p. 125. 
agencies in requiring projects to have "broader impacts" or "translation" articulated. If all projects lay out the implications for longer-term thinking, that would be good.

As a Congressional Fellow for two years and in work with federal judges' education programs and other policy makers, I saw presentations of closely focused case studies that were contextualized very effectively. Specifics matter in persuading policy makers, and one person's grand theory is just as ignorable as another person's. What does not work is little studies without connection. For addressing climate change, as the authors clearly want historians to do, one study or another is not enough. Whether it's how the Netherlands long ago built dikes that allow people to live below sea level or how Venice has responded to flooding at particular times, individual cases do not make a pattern. So, whether looking at the longer or the shorter term, what is most important is that historians identify and discuss patterns, causes, and effects. Historians are in a great position to discuss change over time and how some responses have proven effective or not with respect to different desired goals or outcomes.

The third main theme of the book is the most important, the least well developed, and seems to have attracted the least attention. To help inform discussions about how to manage rising water, for example, or any other public interest, we need data. And we need data from separate stories linked to allow interpretation across longer time scales and other relevant variables. Guldi and Armitage discuss Guldi's Paper Machines tool for using topic modeling to identify patterns. This is a start, but only that.

The digital humanities need to curate data in a repository, provide metadata to make the data findable, connect data from different projects (interoperability), and provide tools for interpreting and visualizing results. Researchers are working to identify patterns of innovation across large areas of science with identification of common structures. Others are systematically harvesting novel or often overlooked types of data - such as acknowledgment sectionsto identify links between research communities. We can start to see what variables contribute to effective innovation or social change, patterns of evolving concept development, evolving networks of collaborators, and so on. Digital history of science provides exciting examples of work in progress. ${ }^{23}$ By working together, we can link individual successes and see the long term.

Two problems remain, however. First, even The History Manifesto itself, in arguing for a data-rich approach, fails to show how the authors are using aggregated data-or indeed doing much more than asserting that Guldi's tool is useful. It is; but there is so much more. We need to see the results that become possible with digital and computational approaches. Second, while some historians of science have been leaders in digital humanities work, many more have resisted. They don't know how, don't have access to a repository, or don't know what metadata standards to use. The professional societies for history of science should provide more help.

We still lack tools, for example, to develop mutually agreeable authority files to establish standards and help resolve ambiguities in word meanings or names. And we need collaborative networks to connect researchers and data across individual projects. To this end, Colin Allen at Indiana, Manfred Laubichler at Arizona State, and Stephen Weldon and Kerry Magruder at Oklahoma are leading efforts to establish a digital HPS network to develop tools and distribute them through open-access and open-source agreements.

Yes, historians of science need to unite! There is "a world to win - before it's too late." That is a world of data, where individual small projects can become linked open data with tools to collect, curate, archive, and thereby connect and interpret, grounded in rich and deep history. This is the path to public impact by historians of science.

\footnotetext{
${ }^{23}$ See http://digitalhps.org.
} 